\title{
Book Selection, Collection Development, and Bounded Rationality
}

\section{Charles A. Schwartz}

A model of how librarians may actually go about book selection is presented in three ways: bounded rationality, tacit knowledge, and symbolic content. It is based on the garbage can decision process widely used in political and educational organizations, which tend to have openended goals, problematic preferences, hazy technology, and poor feedback. The proposed model is reconciled with the modern-day concept of intelligent choice.

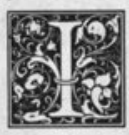

nterest in developing a decision-making model of the book selection process has grown because of dissatisfaction in some circles with the traditional selection literature, particularly its broad surveys of principles and criteria. ${ }^{1}$ Over the past decade, writers have criticized this literature for consisting of "superficial and self-evident generalities"'2 that leave the reader "wondering which criteria are most important and how to apply them. ${ }^{13}$ At first glance, it is not clear that the newly proposed models have much in common. Some are quantitative and would require, if feasible, computers to work, while others are interpretive and rely on intuition. A closer look, however, indicates that they are remarkably similar in scope and methodology.

In scope, the proposed models cover much the same ground as the older surveys. The focus of inquiry, chiefly on bibliographic factors and collection goals, has not been materially clarified or advanced beyond the point reached decades ago.

In methodology, however, the models share a set of theoretical concerns uncharacteristic of the traditional literature. One is classical rationality, defined as simply a procedure for deciding what is correct behavior by relating means systematically to ends. ${ }^{4}$ Closely associated is normative analysis, a prescriptive approach to modeling along the lines of "all rational actors in such-and-such a situation will believe or act in such-and-such a way."

This article takes a different approach to modeling the selection process. Its scope is expanded, beyond the features of a book or a collection policy, to comprise human limitations and their organizational consequences. The assumption of classical rationality is replaced by the concept of bounded rationality, formulated by Nobel Laureate Herbert Simon to denote our inability to deal with all facets of a choice situation. ${ }^{5}$ Concomitantly, normative bias about the way things "should" be done is superseded by behavioral analysis of certain fundamentally ambiguous properties of the selection process. These properties include:

1. open-ended goals for collection development but few measurable objectives or other standards for success;

2. problematic preferences owing to the extraordinary growth in scholarly publish-

Charles A. Schwartz is Social Sciences Librarian at the Fondren Library, Rice University, Houston, Texas 77251. The author wishes to thank David Kaser, Judith Serebnick, and Herbert White for their comments on an earlier draft of this paper. 
ing over the past several decades, and to the broad question of assessing its intellectual quality;

3. hazy technology for writing or using book reviews; and

4. little or no feedback about the eventual use or value of a given selection.

For collection development as a whole, the addition of a fifth property-fluid participation-provides a so-called garbage can process model in which several streams of problems, choices, and decision makers flow through relatively independent organizational channels.

The classical theory of rationality was not designed to handle such properties, and has never handled them satisfactorily. ${ }^{6}$ Indeed, the issue is no longer how people can hope to relate means systematically to ends, for nearly every social science recognizes that in the face of even moderate uncertainty over measures of value, striving for theoretically correct courses of action is neither feasible nor sensible. Rather, the issue is whether people operate reasonably within real-world constraints. ${ }^{7}$ By considering book selection in a framework of bounded rationality, this article seeks to reexamine a few presumptions of our craft and to make the use of subjectivity somewhat less of a mystery, somewhat more of a technique.

\section{"Those who want to understand book selection in behavioral terms face what seems to be an unsolvable problem: that 'selection is always a private, cognitive activity that does not submit to precise observations or delineation.' "}

The model set forth here is developed in five main parts. Part one assesses previously proposed schemes of classical rationality in book selection. Part two outlines new approaches to rational choice behavior. Part three applies a particular approach-bounded rationality in a garbage can decision process-to book selection. Part four describes the role of tacit knowledge and the concept of intelligent choice. Finally, part five presents an overview of theoretical prospects in this field and suggests a few areas for future research.

\section{CLASSICAL RATIONALITY}

Those who want to understand book selection in behavioral terms face what seems to be an unsolvable problem: that "selection is always a private, cognitive activity that does not submit to precise observation or delineation. ${ }^{\prime 8}$ This problem can be managed only by making some assumption about a hypothetical bibliographer's cognitive processes. If no simplifying assumption is made-and not every writer who is critical of the traditional selection literature makes such an assumption-no behavioral model is possible. For example, Hendrik Edelman in a well-known essay (on collection development by classification of library materials) takes the position that, because "selection will be made by different people or even groups of people," a "consolidated selection practice statement is out of the question."

The assumption of classical rationality holds that an individual identifies objectives (say, of collection development), searches for alternative courses of action, evaluates each alternative in comparative terms, and then chooses the best course (book). This conventional notion is assessed first for quantitative models of the selection process, then for interpretive schemes.

\section{Quantitative Models}

One type of quantitative model centers on numerical judgments. The method used is to compare books by assigning them scores for certain collection criteria. The model of John Rutledge and Luke Swindler, for example, includes six criteria, each with a different range of points to represent their relative importance. Thus, subject matter is worth up to 30 points, intellectual quality up to 25 , and so on for a total possible score of 100 per book. ${ }^{10}$ In more elaborate fashion, the John DePew model is a combination of a flowchart having dozens of decision boxes, some politi- 
cal in nature, and an equation of fifteen variables for calculating a book's numerical score. ${ }^{11}$

The second type of quantitative model depends on probability distributions. Robert Losee proposes that books be ranked according to the statistical range of certain bibliographic features whose parameter values would be computed from machine-readable cataloging (MARC) records, both for previously selected and rejected books. Given the size of new book production in the United States (some 50,000 titles annually), this scheme would seem to require a database of overwhelming proportions. Losee's hypothetical example, however, refers to a tiny, carefully defined situation in which an art history bibliographer would make selections by just three factors: a book's height, the number of times the term art appears in a review of the book, and whether a faculty member recommended the book. These factors are assumed to have normal, Poisson, and binary distributions, respectively. ${ }^{12}$

Although such models purport to provide rationality to the selection process, there is no evidence that they are either theoretically sound or a sensible guide for practitioners. In this field of library work where personal theory and practice are allied, these models generate needlessly complex analysis, entailing what economists call the "excessive costs of persnickerty calculation, ${ }^{\prime 13}$ and they overlook or ignore basic principles for making an "optimally imperfect decision." ${ }^{14}$

The principle of dominance pertains to an obvious choice situation, one in which a book (or other option) is easily evaluated on the basis of a few salient criteria. Because of this principle, complex analysis is unnecessary except with respect to nondominant options. ${ }^{15}$ Although this practical aspect of selection methodology is disregarded in quantitative models (as if all books were tough choices), it is taken for granted by some publishers. Thus, it is not uncommon for university presses to print only a few thousand copies of a book to be sold at a high price because the academic library "market is assumed to be both captive and inelastic." ${ }^{16}$ Apparently, the same assumption underlies inflation of institutional over individual subscription rates for scholarly journals. ${ }^{17}$

Two additional principles can be described in terms of a trade-off between precision and relevance of selection criteria. On the one hand, the RutledgeSwindler and the DePew models focus, for the most part, on relevant criteria but misrepresent them by an unwarranted emphasis on precision. Such emphasis is known as the fallacy of misplaced concreteness. ${ }^{18}$ It begins with the presumption that good decisions require precise measures of alternative choices. Where the essential numbers are of doubtful validity, however, there is little point in characterizing a decision process as rational in those terms. Rutledge and Swindler concede that a "decision to assign a specific score [to a book] will be determined by subjective judgments," yet they gloss over the incongruity of this numbers game by dubbing it an art of selection. ${ }^{19}$

In the DePew model, the numbers game is extended to political affairs, such as whether a book requester is a power base or a troublemaker. Even the judgment of the requester is scored on a scale of zero to eleven. ${ }^{20}$ When one considers the objection of many professors to having a library request turned down, one can roughly imagine the aggregated fury of an entire faculty upon discovering its members being graded by librarians for knowledge of scholarly literature.

On the other hand, the Losee model uses quantitatively precise but largely irrelevant selection criteria. Substituting literature-wide probability distributions for individuals' numerical judgments does not alleviate the fallacy of misplaced concreteness but rather compounds it by the convenience of reverse logic. ${ }^{21}$ Such logic starts with the methodology that is most agreeable, or most in accord with one's notion of rationality, and then moves from the predetermined scheme backward to find selection criteria for which the scheme is relevant. In his discussion of normal distributions, for example, Losee cites the price, height, weight, and number of pages of a book. These features are physically measurable, some are accessi- 
ble from MARC records, but they are hardly logical choices as the basis for evaluation.

Certain other issues of quantifying the selection process, such as figuring the intellectual quality of a book, are discussed below in section three. For now, attention is turned to the practical side of selection models. Because time is a scarce resource, and the gathering and processing of information involve both economic and opportunity costs, a decision maker must decide how much time and other resources to devote to a choice situation. The basic rule is stated succinctly by philosopher John Rawls: "We should deliberate up to the point where the likely benefits from improving our plan are just worth the time and effort of reflection." 22

This optimization problem of balancing the costs and benefits of complex analysis has not been addressed in any discussion of book selection. While the traditional library literature can do without it, quantitative models of book selection sorely need a practical orientation. Only if one gathers a lot of information about bibliographic details, and then processes it by charts or equations, can one act in a way that the authors of those models would judge to be intelligent. But to obtain that sort of information, one would have to function quite unfittingly. One would become immersed in picayune matters, such as deciding which of fourteen numerical categories best suits a book review (DePew model) or counting the number of times a particular positive or negative word occurs in a review (Losee model). Bibliographers will find, on calculation or reflection, that this would be an unreasonable way of allocating their time, let alone making decisions.

\section{Interpretive Models}

While it is commonplace in the library field to regard selections more or less as the interplay of collection policy and individual judgment, Ross Atkinson is the only writer to have suggested a model of the decision-making process along such lines. Atkinson describes a hypothetical bibliographer as evaluating a book according to an internalized typology of citation (or reference) contexts. Most crucial are the contexts of resolution, categorized as archival (what is known about the collection), communal (what is known about the interests of the clientele), and thematic (what is known about the subject literature). Classical rationality of the interpretive kind is brought into play by a process Atkinson terms the "inevitable weighting in different situations of the three contexts":

Depending upon such factors as the goals of the library, the nature of the subject, the status of the subject within the library, and the predilections of the individual selector, the three contexts will be prioritized. One context will always take precedence over the other two. ${ }^{23}$

What is troublesome about Atkinson's approach is that contexts of resolution do not form a prospective model of the selection process. Rather, they represent afterthe-fact generalizations. It is tempting to evaluate decisions once their outcomes are known, yet philosophers and psychologists agree that we are in constant danger of making errors whenever we try to do so. ${ }^{24}$ This is because such contexts and other schemata-akin to what the late Michael Polanyi called tacit knowledge ${ }^{25}-$ generally form the background of our decisions but remain unspecificable, outside of conscious awareness and therefore "incompatible with introspective or observational access to causal necessity. ${ }^{\prime 26}$

Everyone uses tacit knowledgeintuition together with experience-to make sense of others' behavior and to perform skilled tasks. The nature of tacit knowledge is not well understood, but certain of its characteristics are clear enough. First, it departs in a fundamental sense from the classical theory of rationality: "we can know more than we can tell. ${ }^{\prime 27}$ Whenever we are faced with a choice or a task of any complexity, we do not spell out the key criteria by which all other criteria are to be judged and then apply them in a formal way. Instead, we have an indeterminate range of anticipations and rules of application that cannot be consciously directed.

Thus, in everyday life we can make fine discriminations-recognizing a friend's 
face among a thousand, indeed among a million-without being able to put this knowledge into words. Likewise, Herbert Simon emphasizes in his discussion of bounded rationality how tacit considerations pervade professional life:

In any field of expertise, possession of an elaborate discrimination net that permits recognition of any one of tens of thousands of different objects or situations is one of the basic tools of the expert and the principal source of his intuitions. ${ }^{28}$

In this perspective, book selection has a critical tacit dimension-similar to what a British librarian terms the experienced glance $^{29}$-that cannot be adequately accounted for in classical models of rationality or conventional notions of subjectivity.

A second characteristic of tacit knowledge is the converse of the first: "we sometimes tell more than we can know." ${ }^{\prime 30}$ When people attempt to report on why they made a particular choice, they do not do so by consulting a memory of the cognitive process, for "it is the result of thinking, not the process of thinking, that appears spontaneously in consciousness. ${ }^{\prime \prime 11}$ Instead, people simply make judgments about how plausible it is that a given factor would have influenced the decision. From the standpoint of subjective feelings of prediction and control, plausibility judgments are natural and disconfirming feedback is hard to come by. Nevertheless, such judgments are not based on any true introspection, but are implicit and exist only in use.

Third, tacit knowledge is personal, in the sense of involving one's personality, and also in the sense of being solitary. As a rule, no two persons share the same tacit theories. ${ }^{32}$ The type of considerations that Atkinson focuses on-collection aims, clientele interests, and subject literaturesare familiar norms in the library field, yet far too general to determine particular choices of any complexity to the exclusion of other, nondominant options. Some evidence is provided by the Report of the $\mathrm{Na}$ tional Enquiry into Scholarly Communication, which found no common denominator among seven case studies of the book selection process:
A variety of procedures are employed by the institutions, by item selectors within the same institution, and by the same selectors over time. Indeed, if there are twenty-five selectors in an institution, there are at least twenty-six procedures for item selection. ${ }^{33}$

"No theoretic ingenuity can account for the profound ways in which some people can organize their experiences and reshape their capacities for judging new works."

Finally, the concept of tacit knowledge carries with it mechanisms of learning and maturation that, being only partially translatable into words, cannot be captured in models. Atkinson rightly describes a bibliographer's experience as "constantly evolving, ", 34 yet the essential argument, made many years ago by T. S. Eliot, is that no theoretic ingenuity can account for the profound ways in which some people can organize their experiences and reshape their capacities for judging new works. ${ }^{35}$ Perhaps we should adopt a provisional outlook about "contexts of resolution" and other interpretations of the selection process, remembering with Lord Tennyson that

Our little systems have their day;

They have their day and cease to be.

\section{NEW APPROACHES TO RATIONAL CHOICE BEHAVIOR}

In the social and behavioral sciences, there has been growing interest in making sense of choice situations characterized by abstract goals, ambiguous stimuli, and hazy technology. Such interest has led to development of three interrelated concepts: bounded rationality, garbage can decision process, and loosely coupled system. These concepts have been applied to educational institutions, publishing houses, governmental bodies, multinational corporations, accounting firms, welfare agencies, appellate court systems, military bureaucracies, and research projects. ${ }^{36-44}$ The studies have little to say about libraries directly and only slightly more to 
report by way of broad quantitative findings. But a realistic model of book selection can be found in their systems of thought.

\section{Bounded Rationality}

In the 1950s Herbert Simon and others found that the micro-assumptions of rationality in the classical theory of the firm are contrary to fact. There is no evidence that managers actually equate marginal costs and revenues, or that consumers distribute their purchases in such a way as to maximize their utility. ${ }^{45}$ From this research work arose the concept of bounded rationality, which takes the limitations of the decision maker and the complexities of the environment as central concerns.

Simon has demonstrated that choice behavior does not conform to textbook descriptions because individuals lack the computational capacity as well as the necessary information to act this way. It is not a question of approximation; the shortfall in information-processing capabilities, relative to environmental complexities, is so great that teamwork and even computers are of minor assistance. Decision makers introduce, as reasonable responses, a number of familiar procedures to simplify a choice situation. These include replacing optimal goals with satisficing ones; devising heuristic (rule-ofthumb) strategies, so that selections will be made after searching only a small part of the total choice situation; allocating time and other resources with an eye to the varying quality of decisions; and, with experience, adjusting aspiration levels to the attainable. ${ }^{4}$

\section{Garbage Can Decision Process}

The garbage can analogy is not one of organizational structure, but of a common type of choice situation that appears to defy conventional assumptions of rationality. According to such assumptions, "choice opportunities lead first to the generation of decision alternatives, then to an evaluation of their consequences, then to an evaluation of those consequences in terms of objectives, and finally to a decision. ${ }^{\prime \prime 47}$ There is considerable evidence that this scenario greatly oversimplifies many of the problems that practitioners face, especially in educational and publicsector organizations.

Case studies of the garbage can process typically focus on singular choice instances for group resolution, such as the location of a new medical school or the reorganization of a university curriculum. ${ }^{48}$ With rare exceptions, such studies have not dealt with recurrent, less burdensome decisions at the individual level, like book selection. To illustrate their general tenor and findings, consider the selection of an academic dean. In the garbage can process, goals having to do with the character of the institution-hiring women and minorities, upgrading neglected departments, funding new programs-would typically be taken into consideration in the selection of the dean. ${ }^{49}$ This type of decision is shaped (somewhat like library collection development as a whole) by several relatively independent streams of problems, participants, choice opportunities, and solutions flowing through organizational networks.

At the individual level, the research paper has been accurately described in terms of tacit knowledge and the garbage can process. ${ }^{51}$ Certainly, well-ordered models of scholarly inquiry-formulate a theoretical problem, select an appropriate method, analyze and interpret the results, confirm or deny the theory-are a poor account of the research experience. Robert Merton, dean of Academic sociologists, explains the discrepancy:

[There is a] rockbound difference between the finished versions of scientific work as they appear in print and the actual course of inquiry. . . . Typically, the scientific paper or monograph presents an immaculate appearance which reproduces little or nothing of the intuitive leaps, false starts, mistakes, loose ends, and happy accidents that actually cluttered up the inquiry. ${ }^{52}$

(That sort of contextual information is screened out of scholarly publications by editorial conventions. ${ }^{53}$ )

\section{Loosely Coupled System}

The idea of loose coupling represents the extent of incoherence and disjuncture between organizational means and ends. Writers use it with a variety of garbage can 
decision situations in mind: (1) a relative lack of formal standards, (2) delegation of discretion, (3) occasions in which any one of several means will produce the same end, (4) infrequent inspection or coordination of activities, and (5) the absence of linkages for some theory to be relevant. For example, in educational organizations there is little feedback from ends to means, or feed-forward from means to ends, so the casual connections between the two are not testable. ${ }^{54}$

\section{Bounded Rationality in Book Selection}

Not all behavior within an organization conforms to a single model. In a library, catalogers tend toward a highly programmed mode in the interests of bibliographic control, whereas administrators usually adopt a contextual approach, shifting between bureaucratic and participatory styles. For bibliographers, four perspectives of bounded rationality may make ordinary experience in book selection more explicable. These perspectives-open-ended goals, problematic preferences, hazy technology, and poor feedback-suggest a necessarily more complex, loosely coupled model of means and ends in collection development than that described by conventional theories of rational choice.

\section{Open-Ended Goals}

Libraries have broad, idealistic goals, e.g., "to serve the academic community," but few measurable objectives, time constraints, or other standards for success. If it were possible to change this situation without trivalizing it into a definitional problem, we would want to do so for the sake of personnel management. ${ }^{55} \mathrm{How}$ ever, several recent studies of choice behavior show that, where means-ends relations are essentially ambiguous-as they are in book selection-schemes of explicit objectives are neither representative of stable preference orders nor suitable for creative interpretation of what the goal might mean..$^{56}$ About the only way of making open-ended goals tractable is to devise loosely coupled subgoals (such as collection development policies broken down by subject descriptors). The aim of systemizing selection goals and their criteria into some grand model appears unrealistic.

\section{Problematic Preferences: Book Proliferation}

Bibliographers seem destined to face an increasing gap between library budgets and potential acquisitions owing to the extraordinary growth of the scholarly enterprise in the past several decades. The number of new books published in the United States displayed no clear trend during the first half of the century, hovering around 10,000 titles a year. From 1950 to 1975 , however, the number of new titles published annually increased fourfold, and by the mid-1980s it surpassed the 50,000 mark (in addition to some 100,000 titles imported yearly). Moreover, in the decade after 1975 the average price of hardcover volumes just about doubled. ${ }^{57}$

In an extensive survey of these publishing trends, the American Academy of Learned Societies concluded that "finding ways to help librarians cope intelligently with the flood of material engulfing them is central to any rational solution to the problems of scholarly communication." ${ }^{\prime \prime 58}$ This task must be carried out in the face of downward pressures on the total number of books that libraries are willing to buy-given the sharp increases in the number and cost of journals, continuing reductions in federal grants for acquisition programs, and other constraints on financing higher education.

\section{"Although evaluation of intellectual quality is an integral part of book se- lection, there has been virtually no discussion of this problem in the li- brary literature."}

\section{Problematic Preferences: \\ Intellectual Quality}

Although evaluation of intellectual quality is an integral part of book selection, there has been virtually no discussion of this problem in the library litera- 
ture. Perhaps a general assumption has been that "Quality is rather like obscenity: ... defining [it] is a futile exercise, even though a group of individuals may be able to form a consensus on the quality of a particular item. ${ }^{\prime 59}$ While the concept cannot be rolled into a neat definition, such a definition is neither necessary nor appropriate. A wide range of studies show that (1) well-established criteria of intellectual criteria do exist but that (2) a group of individuals, even subject experts, fully committed to the same criteria will likely disagree on their judgments of a given work.

Several large-scale surveys of journal editors and referees in the social and behavioral sciences have found a striking consensus on the importance of a limited number of criteria for evaluating manuscripts. The main norms include illumination of a salient problem, generalizability, comprehensiveness, practicality, originality, and integration of diverse theoretical perspectives into a single model. ${ }^{60}$ One survey characterized research milestones in just three attributes: providing a different direction for researchers or practitioners, bringing in this new "truth" from outside a sterile field, and treating a specific and enduring problem. ${ }^{61}$

Such criteria and attributes, like any values, are equivocal by nature and, when employed together, are weighed differently by individuals. For example, in a survey of 299 members of editorial boards for psychology journals, there was only moderate agreement on evaluations of particular manuscripts and even less correlation between those evaluations and subsequent judgments by other readers, as measured by citation counts. ${ }^{62}$ More generally, Robert McC. Adams of the $\mathrm{Na}$ tional Research Council has found that this absence of a clear consensus on the relative merits of scholarly works "bears little relation to field, across the entire span from the physical to the social sciences." ${ }^{\prime 63}$

The acceptance or popularity of a piece of research in the social and behavioral sciences has little to do with its scientific support. Instead, what counts as knowledge may be only loosely coupled to empirical evidence, internal consistency, or predictive power. ${ }^{64}$ Some observers suggest that pictorial models with high reliability but low precision (such as the broken window theory of neighborhood decay or the Jcurve theory of political revolution) are especially useful for the handling of complex concepts. ${ }^{65-67}$ Others contend that the most interesting studies are those with the greatest distance between independent and dependent variables, e.g., the prediction that single vehicle automobile accidents are influenced by suicide stories on television soap operas. ${ }^{68}$

Intellectual quality is often associated with iconoclasm, the breaking of established theoretical premises. In this view, the most important works are those that stand in stark relief to taken-for-granted concepts:

By denying the validity of routinely held cognitive assumptions, a theory attracts attention, forcing its audience to re-evaluate subject matter from a novel viewpoint. New propositions are interesting or uninteresting only in relation to this baseline of traditionally accepted knowledge. $^{69}$

The corollary is that a piece of research will be considered unimportant if it merely proves, however carefully, what is already well known. This is particularly true for practitioners who need ways of reducing the uncertainty of problems where common sense can go either way:

Managers are accustomed to making decisions under relatively high levels of uncertainty. They have little interest in the kind of knowledge about causes and effects that merely increases the certainty of an already apparent relationship. They are decidedly more interested in either conceptual knowledge that helps them order their thinking about an action area or plausible hypotheses that have not previously occurred to them. ${ }^{70}$

Iconoclasm, in the broadest sense, underlies Thomas Kuhn's theory of scientific revolutions as a succession of traditionbound periods in which an older paradigm is replaced in whole or in part by an incompatible new one. The significance of paradigms is that they give rise to what Kuhn calls normal science: "law, theory, application, and instrumentation together" to form coherent traditions of re- 
search. ${ }^{71}$ Paradigm change depends not on the logic of experimental evidence but rather on techniques of persuasion: the paradigm's promise to solve problems, its aesthetic qualities, or something else to convince others that it is on the right track. Whereas Kuhn professes faith that paradigm choices are rational, other social philosophers contend that "our standard theories of what constitutes rationality are not adequate to illuminate this complex process."

\section{Hazy Technology: \\ Book Reviews}

Technology is knowledge, not only of how to make things but also of how to make choices. Two types of studies have been done to gauge the reliability of the review process in scholarly communication and in book selection. One type concerns book criteria, the other reviewer bias.

Some of the reports on book criteria date back several decades, but they generalize well with more recent studies that indicate reviews are overwhelmingly positive though somewhat superficial. For example, Dean Champion and Michael Morris, in an analysis of 2,378 reviews in three sociological journals over a 23-year period (1949-71), found only 18.2 percent of the reviews to be negative in their overall appraisals. "The most frequent criticisms centered upon substance ( 29.4 percent), while theory and methodology received less than 5 percent emphasis, respectively." ${ }^{\prime 73}$ The paucity of sound criticisms was attributed to an implicit norm of reciprocity in the review process and a consequential "fear of adverse reaction from one's colleagues." 74

Similar results, though with different conclusions, were obtained by Beth Macleod in an analysis of 2,600 reviews in Choice and Library Journal in 1978. Only 6 and 9 percent of the reviews in the respective journals were negative recommendations. ${ }^{75}$ More often than not, reviewers made no mention of the quality of writing, depth of analysis, nature of research, or uniqueness of the book. Less than 10 percent of reviewers stated and expressed a judgment about the author's thesis. Macleod found that "reviewer anonymity [which was the procedure in Choice at that time] does not appear to make for more critical reviews." She concluded, instead, that the preponderance of favorable recommendations was essentially a matter of initial editorial screening of doubtful titles. ${ }^{76}$ This conclusion is supported by the apparent agreement on the part of editors that if a book is bad, it is not worthy of a review. ${ }^{77}$

Reviewer evaluation of books often is challenged as unreliable. This is hardly surprising in the social and behavioral sciences, given the diversity of methodological orientations and the lack of law-like generalizations. Although it is widely recognized that uncertainty in the theoretical sphere sometimes is resolved by reference to social criteria, such as an author's status, reports on specific patterns of bias are largely inconclusive. Some patterns are contradictory, such as generational effect (prestigious reviewers tend to evaluate prestigious authors particularly well) as opposed to noblesse oblige (the higher the prestige of the reviewer relative to that of the author, the better the review).$^{78}$ Other patterns are marginal, e.g., Macleod's finding that "reviewers [of both sexes] were slightly more likely to criticize a book by a woman for its shallowness, and to praise a book by a man for its depth.",79 Overall, the reports suggest an improved situation since the 1950 s and 1960 s, when a negative review might impugn an entire school of thought. ${ }^{80}$ Now the greatest criticism tends to come from within, rather than outside of, the author's own theory group. $^{81}$

By and large, people recognize the haziness of book reviews, as indicated by the adage that " bad reviews are better than no reviews at all." Apparently, the tenor of reviews in the social sciences has little impact on book sales or library circulation. ${ }^{82}$ Given the widespread and unavoidable differences in evaluation of scholarly works, particularly at the time of publication, "one review is very likely to give a rating far from the mean, and even three or four reviews cannot be relied upon to represent the central tendency of the total ratings. ${ }^{183}$ This is not to say that reviews are uninteresting or unhelpful, but 
simply-with reference to quantitative models of book selection-that "a totally inappropriate procedure is to derive a general rating from a review and to use that rating mechanically in the evaluation process. $^{\prime 84}$

\section{"Feedback is a concept that has little practical bearing on book selection as a routine process."}

\section{Poor Feedback}

Feedback is a concept that has little practical bearing on book selection as a routine process. It is treated in the library literature in two distinct ways: performance appraisals of a general kind for individuals, and collection use studies as a measure of organizational effectiveness. We know, for example, that past book use tends to predict future use, and that the most recent materials likely receive the most use. ${ }^{85}$ Such findings, as well as use statistics, are helpful for collection management from a retrospective standpoint, as in deciding what to discard or to send to storage. But they are not conducive to book selection in a prospective, singular sense, as in identifying specific titles to acquire.

Indeed, it is difficult to imagine a workable feedback mechanism for bibliographers based on collection statistics when one considers the time and trouble of preparing such feedback studies compared to those of tacit knowledge. Further, the samples used in these studies are of limited significance, inasmuch as record book use in most libraries is low, around the 50 percent mark. Also to be considered is the "heavy measure of conservatism" entailed in providing for fresh patron interests. ${ }^{86}$

\section{A MODEL OF BOOK SELECTION}

A model of book selection-drawing in part on the previous text-is described below in terms of three main aspects: bounded rationality in a garbage can deci- sion process, tacit knowledge, and symbolic content.

\section{Bounded Rationality}

There is no reason to suppose that there is a single decision process to which all instances of book selection (or rational choice generally) should conform. Collection goals are varied and imperfectly understood. Choice alternatives are sometimes dominant, sometimes problematic. Technology is hazy. Performance measures are vague. Decision quality cannot be evaluated autonomously but rather requires a long period to establish and depends to some extent on others' decisions. Even with careful analysis, feedback is ambiguous. As a rule, it is virtually impossible to define a criterion of rationality for this type of situation (or, what amounts to the same thing, to provide a solution to the garbage can decision process).

A partial exception seems to establish this rule. Mention was made above of the heuristic maxim articulated by Rawls, that we should deliberate on a choice up to the point where the likely benefits of analysis are just worth the time and trouble. This would appear to be unassailable logic. Yet, because decision makers acting under uncertainty routinely ignore it for intelligent reasons (see discussion below on symbolic content), one can plausibly argue that it is deficient not only as a descriptor of behavior but also as a criterion of rationality.

The general point to be emphasized is that the assumption of classical rationality is not appropriate for book selection and should be replaced by the concept of bounded rationality in a garbage can decision context, given our inability to deal with all facets of a choice situation.

\section{Tacit Knowledge}

The ideal of a known, systematic, and justifiable cognitive process, as suggested in Atkinson's interpretive model, does not exist. Instead, reliance must be placed on tacit knowledge, whose basic premises differ sharply from such an ideal. Tacit knowledge accredits the human capacity to acquire knowledge by steps one cannot specify, it allows for choices to be made 
within an intuitive framework that is largely personal, and it accepts the fact that such intuitions are incapable of proof or disproof. ${ }^{87}$

An interpretive model, by contrast, expresses more the human ability to form post factum theories of one's own behavior than an ability to relate means to ends in a prospective manner. ${ }^{88}$

We have already considered the methodological problems and excessive costs of quantitative models of classical rationality in book selection. There remains an issue of decision logic. The common presumption of the quantitative schemes is that once one has minutely examined and numerically scored different features of a book, one has mastered the whole. Underlying this notion is the logic of positivism: If you cannot measure, your knowledge is meager and unsatisfactory. With computers called in to handle all the numbers, book selection becomes viewed as an engineering problem; in Losee's model, if a change in collection development policy requires computer reprogramming, "human selection of new books will be necessary for a time." 89

However, any attempt to break a book down into numerous variables that can be analyzed separately misses the essence of knowledge and literature: the whole is greater than the sum of the parts. ${ }^{90}$ In this perspective of evaluating a work as a coherent whole, we return to a critical tacit dimension of the selection process-the experienced glance-that cannot be established by argument, but is rather something known directly to the practitioner. "Imitation offers guidance to it, but in the last resort .... we alone can catch the knack of it; no teacher [or model] can do this for us.",91

\section{Symbolic Content}

In at least one respect, book selection (along with certain other kinds of organizational behavior) confounds both the classical and the bounded models of rationality. This has to do with the symbolic requirements and signaling opportunities of choice situations in a garbage can decision process.

As we have seen, classical rationality is outcome oriented. Primary attention is placed either on systematic analysis of ends and means to find the best possible decision (quantitative models), or on careful reflection to find the most likely reason for a given decision (ințerpretive models). Bounded rationality, on the other hand, takes an opposite approach. It attributes special value to decision efficiency. Heuristic devices and minimum, or satisficing, criteria are emphasized as reasonable responses to limitations of time and information-processing capabilities.

It makes little sense to focus on outcomes in the book selection process, as though selections were discrete or salient events, given the stream of selections year after year and the lack of feedback. Nor is it advisable to stress the practical side of decision making by showing how the problematic character of selections might be decreased by weakening the requirements for rational choice. This is because the central purpose of book selection for the practitioner may be neither outcomes nor efficiency; rather, the main point may be the process itself:

Where the substantive outcome has relatively low salience for many participants or where it is difficult to establish decision efficacy by observing outcome effects, we would expect process pleasures to become particularly relevant. ${ }^{92}$

In such a view, the way in which a bibliographer goes about his or her work may be explicable only if we recognize that a decision process is an arena for exercising social values, for displaying competence, and for exhibiting appropriate behavior with respect to a core ideological construct of modern life: the concept of intelligent choice. ${ }^{93}$

Where knowledge of inputs is incomplete and, at the same time, outcomes are ambiguous, conspicuous consumption of information may be a sensible strategy. For a bibliographer, reading book reviews serves, in part, to provide a ritualistic assurance that proper attitudes about collection development exist. For an administrator, gathering information, asking for information, and justifying decisions in terms of information have come to be significant ways of showing that the organization is well managed.

The symbolic value of information is 
probably more common to garbage can decision processes (administration and collection development) than to bibliographic functions (cataloging and circulation). It is probably more common at the top of the hierarchy than at the bottom; and, for bibliographers, it is probably more common in subject literatures lacking paradigms than in scientific fields.

However, this signaling strategy may be compromised-that is, information seeking may be regarded as a sign of indecisiveness or lack of faith-if the organization acknowledges interpretations of decision making that emphasize limited rationality, a garbage can process, and loosely coupled structure. Not surprisingly, symbolic investments in information depend upon conventional conceptions of intelligent choice.

\section{CONCLUSIONS}

Two things can be said on behalf of the foregoing model. It treats book selection as a rather distinct category of a class of decision-making situations well-known in social science literature; and, consistent with that body of research, it does not attempt to explain too much.

There are about sixty studies of the garbage can decision process. Nearly all of them discuss choice situations as dissimilar, nonrecurrent events for group resolution. A few studies, chiefly in public administration, address the garbage can decision process at the level of the individual policymaker, but they maintain the assumption of dissimilar types of choice situations and are content to rely on Charles Lindblom's classic notion-a precursor to bounded rationality-of muddling through. ${ }^{94}$ Until now, no one has considered the garbage can decision process from the perspective of a practitioner, acting alone, who faces the same type of choice situation on a daily basis. Hence, the important role of tacit knowledge to account for intuition together with experience in a book selection model.

It must be realized that the model presented here is an example of nontheory. There is no strict proof of the existence or extent of tacit knowledge; its acceptance "depends on the observation of complex performances which not only do not re- quire conscious direction but which defy attempts to codify rules for success. ${ }^{, 95}$ At the same time, conventional models of book selection, with lists of choice variables overburdened with box scores and process arrows, are not a theoretical explanation of anything. Nor do such schemes, as Simon noted in his Nobel address, "even remotely describe the processes that human beings use for making decisions in complex situations." ${ }^{\prime 96}$ Rather, when individuals and organizations are faced with a profusion of goals and criteria, they behave much like a system with almost no goals at all.

Also, the model in this paper avoids prescriptions. The importance of careful analysis or reflection is itself subject to rationale appraisal and will depend, like so much else, on the individual and the contingencies of his or her situation. ${ }^{97}$ Modeling cannot fruitfully involve the pursuit of such contextual detail. Moreover, a normative approach would require bibliographers' acceptance of fairly rigid norms about what is rational and acceptable behavior. What is so vital to the development of either a normative or an explanatory theory-a paradigm "signaling the gestalt in which the situation is to be seen ${ }^{\prime \prime 98}$ - would be calamitously narrow for book selection.

It may be useful to suggest possible areas of future research. One such area is prompted by the thought that some of the bounded rationality properties described primarily with reference to social and behavioral science books may not fully pertain (1) to collection development in the physical sciences, given the role of normal paradigms for gauging intellectual quality in those fields, or (2) to collection development in the humanities, in view of various cultural establishments of extremely influential reviewing sources. 9

Another area for reconsideration might be serials management. Some writers have proposed methods of classical rationality for journal evaluation that would require, for example, the development of lists of citation rankings or productivity/ cost ratings for scores of fields. ${ }^{100,101}$ No one has really addressed the optimization problem of balancing the costs and benefits of such complex and time-consuming 
analyses. Perhaps the conclusions drawn in this article with reference to book selection do not fully apply to serials management, since journal acquisitions and deacquisitions are more discrete and probably more important decisions.

Further research in the area of collection development might benefit from the adoption of a particular point of viewnamely, that collection development can be described as a garbage can decision process if one adds the dimension of fluid participation. Thinking about collection development in that framework would at least promote frank recognition that there is no general way of evaluating the organizational effectiveness of libraries. Karl Weick, who conceived the idea of a loosely coupled system, once wrote of the need for redirecting our concern to one of effective organizing of the decision process, since the doing of the process itself is what really counts. ${ }^{\text {P }}$

\section{REFERENCES AND NOTES}

1. Examples of this literature include Robert N. Broadus, Selecting Materials for Libraries, $2 \mathrm{~d}$ ed. (New York: Wilson, 1981); Arthur Curley and Dorothy Broderick, Building Library Collections, 6th ed. (Metuchen, N.J.: Scarecrow, 1985); William A. Katz, Collection Development: The Selection of Materials for Libraries (New York: Holt, 1980); and G. Edward Evans, Developing Library and Information Center Collections, 2d ed. (Littleton, Colo.: Libraries Unlimited, 1987).

2. Ross Atkinson, "The Citation as Intertext: Toward a Theory of the Selection Process," Library Resources \& Technical Services 28:109 (Apr.-June 1984). See also Hendrik Edelman, "Redefining the Academic Library," Library Journal 101:55 (Jan. 1, 1976); and Hendrik Edelman, "Selection Methodology in Academic Libraries," Library Resources \& Technical Services 23:33 (Winter 1979).

3. John Rutledge and Luke Swindler, "The Selection Decision: Defining Criteria and Establishing Priorities," College \& Research Libraries 48:124 (Mar. 1987).

4. James G. March, "The Technology of Foolishness," in Ambiguity and Choice in Organizations, 2d ed., ed. James G. March and Johan P. Olsen (Bergen, Norway: Universitetsforlaget, 1979), p.70.

5. Herbert A. Simon, "Rational Decision Making in Business Organizations," in Advances in Behavioral Economics, ed. Leonard Green and John H. Kagel, v.1 (Norwood, N.J.: Ablex, 1987), p.18-47. This article is the lecture Herbert Simon delivered in Stockholm, Sweden, December 8, 1978, when he received the Nobel Prize in Economic Science. For a broader discussion, see Herbert A. Simon, Administrative Behavior: A Study of Decision Making Processes in Administrative Organization, 3d ed. (New York: Free Press, 1976).

6. Simon, "Rational Decision Making," p.25.

7. Helmut Jungerman, "The Two Camps of Rationality," in Models of Thought, ed. Herbert A. Simon (New Haven, Conn.: Yale Univ. Pr., 1979), p.659.

8. Atkinson, "Citation as Intertext," p.109.

9. Edelman, "Selection Methodology," p.35.

10. Rutledge and Swindler, "Selection Decision," p.123-31.

11. John N. DePew, "An Acquisitions Decision Model for Academic Libraries," Journal of the American Society for Information Science 25:237-46 (July-Aug. 1975).

12. Robert M. Losee, "A Decision Theoretic Model of Materials Selection for Acquisitions," Library Quarterly 57:269-83 (July 1987).

13. William J. Baumol and Richard E. Quandt, "Rules of Thumb and Optimally Imperfect Decisions," American Economic Review 54:24 (Mar. 1964).

14. Ibid., p.23.

15. Detlof von Winterfeldt and Ward Edwards, Decision Analysis and Behavioral Research (New York: Cambridge Univ. Pr., 1986), p.388.

16. Walter W. Powell, "Publishers' Decision-Making: What Criteria Do They Use in Deciding Which Books to Publish?"' Social Research 45:230 (Summer 1978).

17. Richard De Gennaro, "Escalating Journal Prices: Time to Fight Back," in Libraries, Technology, and the Information Marketplace: Selected Papers, ed. Richard De Gennaro (Boston: Hall, 1987), p.103-13.

18. Alfred North Whitehead, Science and the Modern World (Middlesex, England: Penguin, 1938), p.74.

19. Rutledge and Swindler, "Selection Decision," p.128. 
20. DePew, "Acquisitions Decision Model," p.243-44.

21. John Kenneth Galbraith, A View From the Stands: Of People, Politics, Military Power and the Arts, ed. Andrea D. Williams (Boston: Houghton, 1986), p.34-38.

22. John Rawls, A Theory of Justice (Cambridge, Mass.: Harvard Univ. Pr., 1971), p.418.

23. Atkinson, "Citation as Intertext," p.115. Emphasis added.

24. For an overview of this literature, see Richard E. Nisbett and Timothy DeCamp Wilson, "Telling More Than We Can Know: Verbal Reports on Mental Processes," Psychological Review 84:231-59 (May 1977).

25. Michael Polanyi, The Tacit Dimension (Garden City, N.Y.: Doubleday, 1966).

26. Kenneth S. Bower, "Intuition and Discovery," in Theories of the Unconscious and Theories of the Self, ed. Raphael Stern (Hillsdale, N.J.: Analytic Press, 1987), p.79.

27. Polanyi, Tacit Dimension, p.4.

28. Herbert A. Simon, "Alternative Visions of Rationality," in Models of Thought, p.108.

29. Kenneth Whittaker, Systematic Evaluation: Methods and Sources for Assessing Books (London: Clive Bingley, 1982), p.49.

30. Nisbett and Wilson, "Telling More," p.247.

31. George A. Miller, Psychology: The Science of Mental Life (New York: Harper, 1962), p.56; cited in Nisbett and Wilson, "Telling More," p.25.

32. Polanyi, Tacit Dimension, p.25.

33. National Enquiry into Scholarly Communication, Scholarly Communication: The Report of the National Enquiry (Baltimore: Johns Hopkins Univ. Pr., 1979), p.143.

34. Atkinson, "Citation as Intertext," p.114.

35. T.S. Eliot, The Use of Poetry and the Use of Criticism (Cambridge, Mass.: Harvard Univ. Pr., 1933), p.6-9.

36. See, for example, Michael D. Cohen, James G. March, and Johan P. Olsen, "A Garbage Can Model of Organizational Choice," Administrative Science Quarterly 17:1-25 (Mar. 1972); Karl E. Weick, "Educational Organizations as Loosely Coupled Systems," Administrative Science Quarterly 21:1-19(Mar. 1976); March and Olsen, Ambiguity and Choice; Frank W. Lutz, "Tightening Up Loose Coupling in Organizations of Higher Education," Administrative Science Quarterly 27:653-69 (Dec. 1982); and Michael D. Cohen and James G. March, Leadership and Ambiguity: The American College President (Boston: Harvard Business School Press, 1986).

37. Walter W. Powell, Getting Into Print: The Decision-Making Process in Scholarly Publishing (Chicago: Univ. of Chicago Pr., 1985).

38. See, for example, James G. March and Johan P. Olsen, "The Uncertainty of the Past: Organizational Learning Under Ambiguity," European Journal of Political Research 3:147-71 (June 1975); James G. March and Johan P. Olsen, "What Administrative Reorganization Tells Us About Governing," American Political Science Review 77:281-96 (June 1983); John S. Dryzek, "Don't Toss Coins in Garbage Cans: A Prologue to Policy Design," Journal of Public Policy 3:345-67 (Oct. 1983); Jeffrey L. Pressman and Aaron Wildavsky, Implementation, 3d ed. (Berkeley: Univ. of California Pr., 1984); and James G. March and Johan P. Olsen, "The New Institutionalism: Organizational Factors in Political Life," American Political Science Review 78:734-49 (Sept. 1984).

39. Geert Hofstede, "Angola Coffee-Or the Confrontation of an Organization with Changing Values in Its Environment," Organization Studies 1:21-40 (1980).

40. D. J. Cooper, D. Hayes, and F. Wolf, "Accounting in Organized Anarchies: Understanding and Designing Accounting Systems in Ambiguous Situations," Accounting, Organizations, and Society 6:175-91 (1981).

41. B. Gummer, "Organized Anarchies, Loosely Coupled Systems, and Adhocracies: Current Perspectives on Organizational Design," Administration in Social Work 6:77-84 (1982); and D. Brannon, "Decision-Making in Public-Welfare: Scientific Management Meets Organized Anarchy," Administration in Social Work 9:23-33 (1985).

42. Lawrence B. Mohr, "Organizations, Decisions, and Courts," Law and Society Review 10:625-42 (Summer 1976).

43. Alan Ned Sabrosky, James Clay Thompson, and Karen A. McPherson, "Organized Anarchies: Military Bureaucracies in the 1980s," The Journal of Applied Behavioral Science 18:137-53(1982); and Ambiguity and Command: Organizational Perspectives on Military Decision Making, ed. James G. March and Roger Weissinger-Baylon (Marshfield, Mass.: Pitman, 1986).

44. Joanne Martin, "A Garbage Can Model of the Research Process," in Judgment Calls in Research, ed. Joseph E. McGrath, Joanne Martin, and Richard A. Kulka (Beverly Hills, Calif.: Sage, 1982), p. 17-39.

45. Herbert A. Simon, "Theories of Decision Making in Economics and Behavioral Science," The 
American Economic Review 49: 253-83 (June 1959); and Simon, "Rational Decision Making," p.42-43.

46. Gary S. Beck, "A Theory of the Allocation of Time," The Economic Journal 75:493-517 (Sept. 1965); Steffan Burenstam Linder, The Harried Leisure Class (New York: Columbia Univ. Pr., 1970), ch.6; and James G. March, "Bounded Rationality, Ambiguity, and the Engineering of Choice," Bell Journal of Economics 9:587-608 (1978).

47. Cohen, March, and Olsen, "Garbage Can Model," p.2.

48. Kare Rommetveit, "Decision Making Under Changing Norms," in Ambiguity and Choice, p.140-55; and James G. March and Pierre J. Romelaer, "Position and Presence in the Drift of Decisions," in Ambiguity and Choice, p.251-76.

49. Johan P. Olsen, "Choice in an Organized Anarchy," in Ambiguity and Choice, p.82-139.

50. J. M. Ziman, Knowing Everything About Nothing: Specialization and Change in Scientific Careers (New York: Cambridge Univ. Pr., 1987), p.73.

51. Martin, "Garbage Can Model of the Research Process."

52. Robert K. Merton, On Theoretical Sociology (New York: Free Press, 1967), p.4. See also James H. Austin, Chase, Chance, and Creativity: The Lucky Art of Novelty (New York: Columbia Univ. Pr., 1978), p.xii.

53. Contemporary Classics in the Social and Behavioral Sciences, ed. Neil J. Smelser (Philadelphia: ISI Press, 1978), p.vii-viii.

54. Weick, "Educational Organizations," p.5; and Kim Cameron, "Critical Questions in Assessing Organizational Effectiveness," Organizational Dynamics 9:70-71 (Autumn 1980).

55. For a general discussion, see Herbert S. White, Library Personnel Management (White Plains, N.Y.: Knowledge Industry Publications, 1985).

56. March, "Bounded Rationality," p.595.

57. Oscar Handlin, "Libraries and Learning," The American Scholar 56:205 (Summer 1987); and National Enquiry, Scholarly Communication, p.85-87,149.

58. National Enquiry, Scholarly Communication, p.13.

59. Bert R. Boyce and Danny P. Wallace, "In Defense of 'Ignorant Drivel,' " American Libraries 18:654 (Sept. 1987).

60. Janet M. Chase, "Normative Criteria for Scientific Publishing," American Sociologist 5:262-65 (May 1970); Duncan Lindsey, The Scientific Publication System in Social Science (San Francisco: Jossey-Bass, 1978); Wirt M. Wolff, "A Study of Criteria for Journal Manuscripts," American Psychologist 25:636-39 (July 1970); and Stephen D. Gottfredson, "Evaluating Psychological Research Reports: Dimensions, Reliability, and Correlates of Quality Judgments," American Psychologist 33:920-34 (Oct. 1978).

61. John P. Campbell, Richard L. Daft, and Charles L. Hulin, What to Study: Generating and Developing Research Questions (Beverly Hills, Calif.: Sage, 1982), p.91-114.

62. Gottfredson, "Evaluating Psychological Research," p.930-33.

63. Robert McC. Adams, "Rationales and Strategies for Social Science Research," Bulletin, American Academy of Arts and Sciences 34:15 (1981).

64. For an overview of this literature, see W. Graham Astley, "Administrative Science as Socially Constructed Truth," Administrative Science Quarterly 30:502-504 (Dec. 1985).

65. Kurt Lewin, "Formalization and Progress in Psychology," in Studies in Topological and Vector Psychology, ed. Kurt Lewin, Ronald Lippitt, and Sibylle Korsch Escalona (Iowa City: Univ. of Iowa Pr., 1940), p.9-42.

66. James C. Davies, "Revolution and the J-Curve," in Violence in America: Historical and Comparative Perspectives, A Report Submitted to the National Commission on the Causes and Prevention of Violence, v.2 (Washington: Govt. Print. Off., 1969), p.547-77.

67. Chris Argyris, "Research as Action: Useable Knowledge for Understanding and Changing the Status Quo," in The Theory and Practice of Organizational Psychology: A Collection of Original Essays, ed. Nigel Nicholson and Toby Wall (New York: Academic, 1982), p.205.

68. David P. Phillips, "The Impact of Fictional Television Stories on U.S. Adult Fatalities: New Evidence on the Effect of Mass Media on Violence," American Journal of Sociology 87:1340-59 (May 1982); cited in Barry M. Staw, "Repairs on the Road to Relevance and Rigor: Some Unexplored Issues in Publishing Organizational Research," in Publishing in the Organizational Sciences, ed. by L. L. Cummings and Peter J. Frost (Homewood, Ill.: Irwin, 1985), p. 98.

69. Astley, "Administrative Science," p.503.

70. Richard E. Walton, "Strategies With Dual Relevance," in Doing Research That Is Useful for Theory and Practice, ed. Edward E. Lawler III et. al. (San Francisco: Jossey-Bass, 1985), p.197-98.

71. Thomas S. Kuhn, The Structure of Scientific Revolutions, 2d ed., enlarged (Chicago: Univ. of Chicago Pr., 1970).

72. Richard J. Bernstein, The Restructuring of Social and Political Theory (New York: Harcourt, 1976), p.93. 
73. Dean J. Champion and Michael F. Morris, "A Content Analysis of Book Reviews in AJS, ASR, and Social Forces," American Journal of Sociology 78:1261 (Mar. 1973).

74. Ibid., p.1257, 1264 .

75. Beth Macleod, "Library Journal and Choice: A Review of Reviews," The Journal of Academic Librarianship 7:27 (Mar. 1981).

76. Ibid., p.28.

77. Lewis A. Coser, Charles Kadushin, and Walter W. Powell, Books: The Culture and Commerce of Publishing (Chicago: Univ. of Chicago Pr., 1985), p.309.

78. William E. Snizek and E. R. Fuhrman, "Some Factors Affecting the Evaluative Content of Book Reviews in Sociology," The American Sociologist 14:108-14 (May 1979).

79. Macleod, "Library Journal and Choice," p.28.

80. Lawrence E. Riley and Elmer A. Spreitzer, "Book Reviewing in the Social Sciences," The American Sociologist 5:358-63 (Nov. 1970); and Norval Glenn, "On the Misuse of Book Reviews," Contemporary Sociology 7:254-55 (May 1978).

81. William E. Snizek, E. R. Fuhrman, and Michael R. Wood, "The Effect of Theory Group Association on the Evaluative Content of Book Reviews in Sociology," The American Sociologist 16:185-95 (Aug. 1981).

82. On the tenor of reviews, see Judith Serebnick, "Book Reviews and the Selection of Potentially Controversial Books in Public Libraries," Library Quarterly 51:390-409 (Oct. 1981); and Coser, Kadushin, and Powell, Books, p.323, 329-31. On library circulation, see John P. Schmitt and Steward Saunders, "An Assessment of Choice as a Tool for Selection," College \& Research Libraries 44:375-80 (Sept. 1983).

83. Glenn, "On the Misuse," p. 254

84. Ibid., p. 255.

85. For reviews of this literature, see Robert N. Broadus, "Use Studies of Library Collections," Library Resources \& Technical Services 24:317-24 (Fall 1980); and Robert W. Burns, Jr., "Library Use as a Performance Measure: Its Background and Rationale," The Journal of Academic Librarianship 4:4-11 (Mar. 1978).

86. Broadus, "Use Studies," p.323.

87. Knowing and Being: Essays by Michael Polanyi, ed. Marjorie Grene (Chicago: Univ. of Chicago Pr., 1969), p.133-34; and Alasdaire MacIntyre, After Virtue: A Study of Moral Theory, 2d ed. (Notre Dame, Ind.: Univ. of Notre Dame Pr., 1984), p.15.

88. Olsen, "Choice in an Organized Anarchy," p.83; and March, "Bounded Rationality," p.593.

89. Losee, "Decision Theoretic Model," p.281.

90. Clifford Geertz, "Blurred Genres: the Reconfiguration of Social Thought," American Scholar 49:165-79 (Spring 1980); and Jon Huer, Art, Beauty, and Pornography: A Journey Through American Culture (Buffalo: Prometheus Books, 1987), p.72.

91. Knowing and Being, p.126.

92. James G. March and Johan P. Olsen, "Attention and the Ambiguity of Self-Interest," in Ambiguity and Choice, p.47. See also Powell, Getting Into Print, p.98-100; Brown and Wildavsky, Implementation, p.247-48; and Lawrence Mohr, Explaining Organizational Behavior (San Francisco: Jossey-Bass, 1982), p.158.

93. Martha S. Feldman and James G. March, "Information in Organizations as Signal and Symbol," Administrative Science Quarterly 26:177-84 (June 1981).

94. Charles Lindblom, "The Science of Muddling Through," Public Administration Review 19:79-88 (Spring 1959).

95. Martin X. Moleski, "The Role of Retortion in the Cognitional Analyses of Lonergan and Polanyi," in Self-Reference: Reflections on Reflexivity, ed. Steven J. Bartlett and Peter Suber (Boston: Martinus Nijhoff, 1987), p.220.

96. Simon, "Rational Decision Making," p.42.

97. Rawls, Theory of Justice, p.418.

98. Kuhn, Structure of Scientific Revolutions, p.189.

99. See Richard Ohmann, Politics of Letters (Middletown, Conn.: Wesleyan Univ. Pr., 1987).

100. An excellent source is Robert N. Broadus, "The Applications of Citation Analyses to Library Collection Building," in Advances in Librarianship 7, ed. Melvin J. Voigt and Michael H. Harris (New York: Academic, 1977), p.299-335.

101. See, for example, Donald A. Windsor, "De-Acquisitioning Journals Using Productivity/Cost Rankings," De-Acquisitions Librarian Newsletter 1 (Spring 1976), p.8-10; and Richard De Gennaro, Libraries, Technology, and the Information Marketplace: Selected Papers (Boston: Hall, 1987), p.103-13.

102. Karl Weick, "Re-Punctuating the Problem," in New Perspectives on Organizational Effectiveness, ed. Paul S. Goodman and Johannes M. Pennings (San Francisco: Jossey-Bass, 1977), p.216-17. 